\title{
Development of spectral signature curve for the suspended sediment using spectroradiometer
}

\author{
S.S. RAUT AND B.K. GAVIT
}

\begin{abstract}
Water resources and environment management is important for all living beings on the earth's surface. Capacity of the water resources are reducing due to soil erosion or sedimentation and quality also decreasing due to overflow of the reservoir. The analysis of sedimentation data of Indian reservoirs show that the annual siltation rate has been generally 1.5 to 3 times more than the designed rate and the reservoirs are generally losing capacity at the rate of 0.30 to 0.92 per cent annually (NRSA). Remote sensing is a useful tool for in-situ monitoring of suspended sediments in surface water for a variety of reasons such as the multi spectral nature, large area coverage, and temporal data sets. Considering the necessity of the assessment of the sediment as well as advantage of the remote sensing technique. The present study is taken to develop the spectral signature library for different sediment concentration. These results integrating with satellite data yield significant. A controlled experiment was conducted in outdoors condition with a 40 lt water tank (white painted) having natural sunlight condition. A different soil series viz., Gulvanch, Targaon, Rahuri, Pather etc. were added and suspended in the tank filled with water. A total 10 levels of Suspended Sediment Concentration (SSC) (from 1000 ppm to 10000 ppm) were added for each type of treatment. Reflectance was recorded using an HR 1024 Spectroradiometer, and reflectance factor was computed and analyzed. The linearity in the SSC-reflectance relationship increased with wavelength between 400 and $900 \mathrm{~nm}$. For relationship between suspended sediment concentration and reflectance data four different functions, viz., exponential, linear, logarithmic and power were tried. The best fit model was found to be power by regression analysis.
\end{abstract}

KEY WORDS : Spectral signature, Radiometer, Sediment

How to cite this Article : Raut, S.S. and Gavit, B.K. (2015). Development of spectral signature curve for the suspended sediment using spectroradiometer. Engg. \& Tech. in India, 6 (1) : 19-24. 